Boise State University

ScholarWorks

$1-1-2017$

\title{
On the Heterogeneity of Northern Paiute Directives
}

Tim Thornes

Boise State University 


\title{
7 \\ On the heterogeneity of Northern Paiute directives
}

\author{
TIM THORNES
}

\section{Introduction}

In this chapter, I explore a variety of grammatical constructions involved in expressing or asserting a desired action or outcome-what properly (and traditionally) fall under the functional domain of commands (or directives)-in Northern Paiute (Western Numic; Uto-Aztecan). I also discuss the various situational contexts appropriate to their use and make a preliminary assessment of their historical developments, as both grammatical and sociocultural phenomena. This study is intended to contribute to the typological literature on commands and on nondeclarative speech acts more generally (see, especially, König and Siemund 2007 and Aikhenvald 2010, inter alia).

\section{Exploring directive speech}

Directive speech has been widely observed to iconically relate form with function in its grammar (Brown and Levinson 1987; Givón 1990; Haiman 2003). Illocutionary effort is directly proportional to perceived or presumed social distance between interlocutors. There is ample literature on the topic of defining what constitutes social distance, while illocutionary effort, in its particulars, varies from language to language. Seeking the relevant parameters of variation is, of course, one of the goals of the typological approach.

Another goal of such a study is to seek a connection between grammatical variation and the functional domain reflected in it. If we consider the simple speech act known as the greeting, we see differences in the degree of effort coincident with the social relationship (more elaborate=more formal/distant) or upon broader cultural concerns such as social hierarchy (more elaborate=more hierarchically attenuated). 
Directive speech (including commands proper) may also be approached from this perspective. One approach is to simply elicit command forms from native speakers, arriving at translational equivalents of simple commands in a contact language. Such an approach reveals little of the richness of directive speech, however, which may involve a great deal more subtlety, and involve several grammatical subsystems in the language under study.

A usage-based approach to directive speech allows us to consider a range of socalled command strategies, and in so doing develop hypotheses about the origins and development of dedicated directive speech acts. For this exploration, spontaneously produced speech has been key to discovering and analysing the heterogeneous structures that comprise Northern Paiute directive speech. I invoke the work of others on closely related or neighbouring languages where possible, although the available material relevant to this domain is limited. Since no in-depth exploration of directive speech exists for any Numic language, I will focus my attention on the Northern Paiute materials at my disposal as a starting point. I will supplement my analysis with cognate structures from its nearest relatives to further our understanding of historical developments within Numic and general Uto-Aztecan. Hypotheses regarding these developments are necessarily preliminary until a more thorough comparative study of directive speech across the family can be undertaken.

Following a brief introduction to the language and its grammatical profile, I describe the canonical imperative along with several distinct command strategies, the prohibitive, and non-canonical directives in Northern Paiute. Later sections will take up historical considerations and general implications for a typology of directive speech acts.

\section{The language and its speakers}

Northern Paiute represents the north-westernmost extent of the Uto-Aztecan language family, consisting of around thirty distinct languages spoken from the northern Great Basin region of the western United States through portions of the American South-West, and across central Mexico as far south as El Salvador. It is one of two members (the other being Mono) of the Western Numic branch of the Numic subfamily. Numic languages have historically occupied most of the Great Basin, with the exception of Washo, a language isolate.

The area of Northern Paiute speech includes much of south-east Oregon, northern Nevada, southern Idaho, and California east of the Sierra Nevada mountain range. A major north-south dialect division is made on phonological grounds, but there are differences internal to this division as well as at all levels of grammar. The information presented here stems from work in the northern area and centres upon the dialect still spoken by members of the Burns Paiute Tribe of eastern Oregon, as well as archival materials. 
There are probably no more than 400 speakers of Northern Paiute. In most communities, there reside just a handful of elderly fluent speakers. The vast majority of speakers are over 50 years old.

\section{Preliminaries: Northern Paiute grammatical properties}

\subsection{Morphological and syntactic type}

Northern Paiute is structurally agglutinating and highly synthetic, with verbs being the most morphologically complex word class. The language carries most of the features that typify an SV/AOV language, including postpositions and pre-head modifiers, although there is significant pragmatically determined flexibility and extensive ellipsis of arguments in context.

\subsection{Word classes and grammatical categories}

Nouns and verbs comprise the two large, open word classes of Northern Paiute.

For nouns, number is irregularly marked morphologically only on human nouns. There is no grammatical gender in Northern Paiute, although the language does carry the typical Uto-Aztecan feature of so-called 'absolutive' ${ }^{\text {' }}$ suffixes-suffixes that appear with certain noun roots in their citation form, but not in other morphosyntactic contexts. Northern Paiute also has denominalizing morphology indicating verbal notions like HAVE, MAKE, and WEAR.

The most morphologically complex word class, verbs have the general structure formulated in (1).

(1) Object $=[$ Phasal $[[$ Valence $[$ IP $/[$ Root $]]$ Valence $]$ DIR/ASP $]$ SUB/NMLZ $]$
PRO $=$ AUX THEME STEM

Verbs in Northern Paiute, by and large, fall into fairly strict transitivity classes. These include (1) zero-transitive (mainly weather and other natural phenomena), (2) intransitives that can be classified covertly into two classes, depending upon the semantic outcome of the causative-applicative construction (Thornes 2003, 2013), (3) transitive (generally requiring the addition of the antipassive prefix for object suppression), (4) ambitransitive of the $S=O$ variety (semantically transitive but not requiring the antipassive prefix for object suppression) and (5) ditransitive (in a symmetrical, double-object construction).

A number of high-frequency verbs exhibit the strong stem suppletion common in Native North American languages. The pattern appears mainly sensitive to

1 The use of this label for this particular morphological phenomenon has been widely attributed to Sapir (1930). 
participant ${ }^{2}$ number (singular versus plural) with an absolutive pivot, either the $S$ of an intransitive verb or the $\mathrm{O}$ of a transitive verb. For the three basic posture verbs 'sit', 'stand', and 'lie', we find distinct forms for singular, dual, and plural. ${ }^{3}$

Verbs are rich in morphological markers of aspect and direction, although Northern Paiute is, arguably, tenseless, carrying only what could be considered a relative future tense marker. The historical development of many of these affixes via the language's specialized serial verb construction has been explored in detail in Thornes (2011). Irrealis marking that characterizes some forms of directive speech will be discussed below, as will the nominalizing and subordinating morphology. Northern Paiute verbs also carry several devices for altering, increasing, or decreasing the inherent valence. These may serve, in part, to identify the transitivity class of verbs.

A closed set of basic adjectives that code value, age, and dimension, as well as the lower numerals, share certain morpho-syntactic properties. Chief among these properties is the marking of nominative versus oblique (non-nominative) case. Basic adjectives may also be compounded with noun stems when coding an inherent property or otherwise serving a more restrictive, naming function, and are stripped of case in this context. Colour terms form obligatory compounds with the nouns they modify.

Adverbs and particles form a highly heterogeneous class, morpho-syntactically. Northern Paiute has a wide range of clitic types, which fall mainly into three categories. The first are proclitics functioning as definite determiners and nonsubject pronouns, exemplified throughout the chapter. There are also several second position clitics that carry modal-evidential and some pronominal functions. They participate in several varieties of directive speech, along with irrealis marking. Finally there are a small set of enclitics of narrow scope, indicating polarity, emphasis, and other focus-type functions.

\subsection{Verbs and verb structure}

Complex verb structures are exemplified below and may consist of stem compounding ${ }^{4}$ (example (2)), lexical prefixation of the means and manner (i.e. 'instrumental') type (example (3b)), single word, asymmetrical serial verb constructions (à la Aikhenvald and Dixon 2006) (example (4)), and incorporated phasal auxiliaries (example (5)).

${ }^{2}$ Event number, a verbal aspectual category (cf. Corbett 2000), is also at play.

${ }^{3}$ It is my impression as well that this development is peculiar to Numic languages and is not found elsewhere in Uto-Aztecan.

${ }^{4}$ Several factors distinguish stem compounding from single word verb serialization in Northern Paiute. Formally, the applicative suffix will always follow a stem compound, but attach only to the first (main) verb in a serial construction. See Thornes (2011) for a more detailed list of properties. 
(2) $\ddot{\mathrm{i}}$ =sakwa ka=toissapui $\mathrm{i}=$ sami-tiki-ki you=MOD $O B L=$ chokecherry me=soak-put.sG-APPLIC

You should put the chokecherries in to soak for me. (NK ${ }^{5}$ : Chokecherries)

(3a) su=tokano ni tsipugi-si

NOM=night I emerge-SEQ

(3b) i=tsa-tsipuki me $=$ IP/GRASP-emerge

Once I come out in the night...

Pull me out!

(4) oono tiwau umi na-tiničui-pokwa-'yakwi

at.that.time also 3.pl MID-tell.stories-lie.PL-HAB

And then, too, they would lie around telling stories.

(NK: Root-digging Time)

(5) $\mathrm{ni} \quad \mathrm{mi}=$ misu-makwi-u-kwi

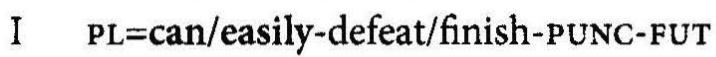

I will easily defeat you all.

(IW: Flying Contest)

Although, synchronically speaking, noun incorporation is not a productive process in the language, several lexical prefixes have nominal origins, typically from body part terms, with stem-compounding as their source construction (cf. Thornes 2003, 2009, 2011).

\subsection{Grammatical relations}

There is no argument agreement in the Northern Paiute verb, although unstressed, object pronominal forms are bound to the overall verb structure as proclitics, as in example (5). A formal syncretism exists between object pronominal proclitics on verbs and the possessor proclitics that attach to nouns, a point related to the language's extensive use of both lexical and clausal nominalization.

Northern Paiute exhibits two core cases, which I label nominative (NOM) and oblique (OBL). These are overtly specified in the form of pronouns and on noun phrase dependents (modifiers and determiner proclitics).

(6) su=udi-?yu naatsi kima-u-gi-na

NOM=tall-NOM boy come-PUNC-CISL-PARTIC

The tall boy is coming this way.

(7) ni $\quad \mathrm{u}=$ punni, $\quad \mathrm{ka}=\mathrm{udi}-\mathrm{u} \quad$ naatsi
I $3=$ see $\quad$ oBL=tall-oBL
I see him, the tall boy.

5 Examples drawn from texts include the initials of the speaker. Texts from the archived materials of others include information about the collection in a footnote. 
Case marking on head nouns appears to have been lost in Northern Paiute, while persisting, marginally, in the other two branches of Numic (Central and Southern).

\subsection{Clause types}

Northern Paiute basic clauses are fairly straightforward. Coordination at the clausal level is accomplished mainly through simple juxtaposition, although converbal marking is a common clause-chaining device. Interrogatives are also straightforward, with clause-initial question words, and the narrow-scope question enclitic $=h a$ for polar questions.

Nominalization is the main strategy in forming a range of subordinate clause types. As a point of empirical fact, it is very rare to find either embedded complement clauses or headed relative clauses in natural discourse (cf. Thornes 2003:441-7 and Thornes 2012). Nominalized subordinate clauses across the family have no doubt given rise to some of the peculiarities we occasionally find in the case marking of core arguments in directive speech in Numic languages. Diachronic issues will be taken up in $\$ 12$.

\section{Note on sources}

Targeted grammatical elicitation and meta-discussion surrounding usage patterns and points of contrast are included and incorporated with caution, in particular since the bilingualism of the most elderly speakers is by no means perfect.

The majority of the data used in this paper are drawn from texts of various genre, both monologic and, to a more limited extent, conversation. Participant observation plays an occasional role in the data gathered here, but challenges are posed by the simple fact that the language is moribund and all modern-day speakers are bilingual in English. As such, the development of a text corpus has played the most significant role in supporting my understanding of the language's rich structure. Text resources also include archived material. All examples drawn from texts or participant observation are cited by the initials of the speaker and include a short title. Archived resources are cited as such.

\section{Commands in Northern Paiute}

The basic, canonical imperative construction-defined here as the morphologically simplest second person directive as well as the one speakers identify as the most commonly used and direct command form-involves a bare verb stem.
(8) yadua!
(9) tinikwihi!
(10) ti-punni!
talk.sG
sing.sG
APASS-see
Speak!
Sing!
Look! 
Stress in Northern Paiute is highly regular, falling on the second mora of the phonological word. In the simple commands above, the primary stressed syllable is perceived as more pronounced (usually uttered at a higher pitch) than in citation.

Occasionally, the verb expressing an event in the imperative is accompanied by the punctual aspect suffix - $(h) u$. In these cases, there is a sharp, falling intonation over the suffix.
(11) kadi-u!
(12) winni-u! stand.sG-PUNC
Stand up!
sit.SG-PUNC
(13) $a=s u^{\prime} a-u$ !
$4^{6}=$ consume-PUNC
Sit down!

Thornes (2003: 322) offers a semantic explanation for the appearance of this suffix based upon the inherent aspect of the verb in question. However it is more likely that the main feature determining the presence versus absence of the punctual suffix is whether or not the event encoded is bounded by an endpoint. Verbal predicates encoding telic (bounded) events take the punctual suffix in the imperative, while those encoding atelic (unbounded) events do not, appearing instead as bare verb stems.

One way to test this hypothesis is by altering the inherent aspect of the base predicate. Compare the following examples, both with the verb habi, the singular form of the posture verb meaning 'lie'.
(14) habi-u!
(15) habi-dabi $(*-u)$ !
lie.sG-PUNC
lie.SG-KEEP.ON(*-PUNC)
Lie down!
Stay/Keep lying down!

In (15), an aspectual suffix implicating sustained effort and duration is deemed semantically (and grammatically) incompatible with the punctual suffix in the imperative.

The punctual suffix is compatible with the irrealis subjunctive suffix -tua, as we see in the warning in (16).

$$
\begin{aligned}
& \text { (16) } \quad \text { ii }=s a ' a \text { wi'l-u-dua } \\
& \text { you }=\text { MOD descend-PUNC-SUBJ }
\end{aligned}
$$

You might fall off!

(NK: Porcupine and Coyote)

The punctual suffix merely identifies the encoded event as bounded.

Some sources (Snapp and Anderson 1982; Norris 1986) have suggested that the punctual suffix serves as the primary means for marking an imperative in Northern Paiute. As demonstrated here, such is not the case. I treat the unmarked form of the

\footnotetext{
6 What I refer to as fourth person represents an object or possessor that is 'very low in topicality' (Thornes 2003: 160), in keeping with the Americanist tradition of obviative.
} 
verb as the basic imperative construction in the language, with the punctual suffix serving to indicate completion of the directed action.

Suppletive verb forms may indicate non-singular addressees, as with the formal three-way verb suppletion of 'sit' in (17)-(19).

(17) namasoa kati-u!

quickly sit.sG-PUNC

Sit down quickly!

(18) mau čigwi-u!

DEM sit.DU-PUNC

Sit down there (you two)!

(19) ma'aatui aata-u!

anywhere sit.PL-PUNC

Sit down anywhere (you all)!

Pluractional CV' reduplication may function like verb suppletion in indicating a non-singular addressee.

(20) $\mathrm{u}=$ =pu-punni!

$3=$ REDUP-see

Look at him (y'all)!

In other cases where no such alternations are available for dual or plural addressees, an overt second person plural pronoun may be used to disambiguate. Interestingly, I have found no examples in my corpus of overt expression of a singular addressee in the canonical (bare stem) context. The addition of the punctual suffix, although common in commands involving telic event types, may best be described as a frequent command strategy in the language, since its use is not limited to imperatives.

I turn now to several other command strategies used in Northern Paiute.

\section{Command strategies}

Directive speech acts in Northern Paiute exhibit several features of formal variation that colour the force of the imperative along dimensions like politeness, urgency, entreaty, and realis expectation, among others. In order to get a fuller sense of the development of directive speech in Northern Paiute, it is important to explore these command strategies, defined as 'non-imperative forms used to express imperativelike meanings' (Aikhenvald 2010: 398).

Command strategies that employ the simple addition of an irrealis marker, either the future suffix $-k w i$ or the subjunctive $-t u a$, are common. Overt expression of the addressee in these cases is optional. 
(21) pa-noo-tua tammi u=hibi-kwi!

IP/WATER-carry-SUBJ 1.pl.inc 3 =drink-FUT

Go and get water so we can drink [it]!'

(Liljeblad 1966: 10)

The co-presence of the punctual and subjunctive markers provides further evidence that the former is just another command strategy, and not a marker of the imperative, as argued above.

(22) maa-ti sawabi iwa hani-u-tua! yabia-ppi!

DEF.PRO-LOC sagebrush much do-PUNC-SUBJ hurry-PERF

Right there put lots of sagebrush. Hurry!

(Liljeblad n.d.: 23)

The following includes overt expression of the addressee, which in this case happens to be a dog, as well as both punctual and irrealis marking.

(23) ï ki-kwi(h)i-u-tua

you IP/BITE-get-PUNC-SUBJ

You fetch!

The following, without any aspectual marking, includes overt reference to the addressee.
'idza-pii
maiku ta=ma'wi!'
$\mathrm{mii}=\mathrm{ka}$.
coyote-MYTH
DEM
1.du.inc $=$ start.fire
QUOT $=$ SO

'Coyote, make a fire for us!' he said.

(PS: tale 2, page 18 , line $145, \mathrm{SLC}^{7}$ )

In variance with what we have assumed to be the default, direct-force commandone that appears only as a bare verb stem or verb phrase without indication of tense, aspect, or mood-we also find second person singular directives like the following (cf. example (2)):

$\begin{array}{llll}\text { (25) ' } \mathrm{i} i=\text { sakwa } & \mathrm{ka}=\mathrm{i}=\text { mia-si } & \mathrm{i}=\text { puh-nagi,' } & \text { mii. } \\ \text { you=MOD } & \text { OBL=1=go-sEQ } & 1=\text { =IP/EYE-chase } & \text { QUOT }\end{array}$

'You should keep watching me where I go,' saying.

(ML: The Five Men Story, $\mathrm{MNC}^{8}$ )

Here the speaker makes overt use of the second person pronoun in addition to the deontic modal enclitic to soften the command issued by the character in this story. It is perhaps the case that the narrator herself is hedging, for the sake of the listener, on whether the command will be followed. Note, too, that in most cases

\footnotetext{
7 Sven Liljeblad Collection: 86-14 Box 25 'Mss Copy of Texts in Northern Paiute', 216 pp. Pete Snapp (PS), speaker, recorded in 1961, Special Collections, University of Nevada-Reno.

${ }^{8}$ From the Michael Nichols Collection of Northern Paiute sound recordings, Marian Louie (ML), speaker, recorded in 1969, California Language Archive, University of California-Berkeley: http://cla. berkeley.edu/
} 
where a modal is included as part of a command strategy, an overt pronoun serves as its host.

In this and countless other Northern Paiute tales, events pivot on the consequences of not following advice or of violating an interdiction (see \$8).

Another variant of the canonical imperative involves the simple addition of the intensifying particle ini to indicate a kind of emphatic permissive command that lends an immediacy to the expected action, as in the following:

(26) 'ini mia! ni mai yongo-kwi,' miu su=simi-'yu ini-na INTENS go I DEM evening-FUT QUOT NOM=one-NOM Say-PARTIC 'Go ahead and go! I'll stay here for the night,' the one said...

(ML: The Five Men Story, MNC)

In the next example from the same text, one man is refusing to violate a food taboo, while at the same time refusing to bar another from doing so:

(27) (u)su='kai ni! ini a=tika!'’ mii $u=$ nimai.

(3) NOM=NEG I INTENS 4=eat QUOT 3=say

$\mathrm{He}_{\mathrm{i}}$, 'Not I! Go ahead and eat it,' saying to him .

In one case found among the archived materials of Sven Liljeblad, the combination is translated as 'please', which seems to contrast, functionally, with the permissive function just described.

(28) ini i=tsa-ha'ni-ki!

INTENS 1.sg.OBJ=IP/GRASP-do/prepare-APPLIC

Please, turn me loose!

(PS: tale 7 , page 124 , line 462, SLC)

The context for the utterance is one where a ghost's skeleton is begging a tree it is snagged on to set it free. Interestingly, the intensive particle ini alone is often used when bidding farewell to someone, with a meaning like 'Go ahead!' or 'Take care!'

Nominalized clauses pervade Northern Paiute grammar as a means of packaging information in running discourse and may also be used to formulate directives. These have the flavour of offering advice.

(29) pisa-ku i=tikapi a=gi'wa'ya-nna, a=yikwi-u-yai

good-oBL $2 . s g=$ food $4=$ =chew-PARTIC $4=$ =swallow-PUNC-HAB

Chew your food well before you swallow it! (Liljeblad, n.d.: 20)

(30) taibo'o iai-na!

white.person caution-PARTIC

Watch out for white people!

(Liljeblad 1966: 16)

In (31), overt expression of the addressee is in the form of the second person pronominal proclitic, and the verb form again includes the participial (nominalizing) suffix $-n a$. 
(31) $\dot{i}=$ tì-buni-nna!

2.sg=APASS-see-PARTIC

Wake up! (lit. your seeing)

(Liljeblad, n.d.: 23)

As with other command strategies, overt expression of the addressee is optional (compare (29)-(30)). Morpho-syntactically this is a possessor-plus-nominalized clause construction functioning as a softer, indirect command strategy.

A directive may also be softened by adding the suffix $-s i$ to the bare verb stem. The following examples contrast this strategy with the more direct, punctual forms.
(a) kima-u!
come-PUNC
Come!

(33) (b) kima-si! kima-si mu'a! come-SEQ come-SEQ grandchild Come (dear)! Come, grandchild!

(b) $\mathrm{ka}=$ paa hibi-si

OBL=water drink-SEQ

Drink the water, OK?

The (a) examples above always bear falling intonation over the punctual suffix, whereas the softened command maintains high, level intonation throughout. My youngest language consultant, a woman in her late fifties, reports using this strategy when speaking gently to children or the infirm.

The most obvious affinity of the form is to the sequential converbal suffix -si. As a counterpart to -na, -si marks the situation expressed by one clause as preceding another, while - na generally implies temporal simultaneity. Verbs so marked carry a connotation of non-finality that one could attribute to the gentle imperative above. English imperatives that imply encouragement or an entreaty, rather than direct action, are often followed by a tag expression, as in 'Go to the store, won't you?' or 'Come along with us, OK?' It is as though one expects verbal agreement after resistance or difficulty in carrying out the directive.

Elsewhere, clauses marked with $-s i$ in Northern Paiute are used strategically in cooperative discourse as a back-channelling device to encourage a narrator to continue. Interactional doublets like the following are common:

(34a) $00=\mathrm{ka}$ nabiwo'ya-kwinai-u-si?

thus=KA MID.drag.lengthwise-throw.SG-PUNC-SEQ

Listener: Was that when he was dragged out?

(34b) $00=k a$ nabiwo'ya-kwinai-u-si, yaisi...

thus=KA MID.drag.lengthwise-throw.SG-PUNC-SEQ

Narrator: That's when he was dragged out, and...(he was crying)

(PS: tale 9, page 183 , lines $27-9$, SLC)

The non-final, incomplete 'feel' of a verb in this form may motivate its use in a gentle imperative context. 
There are, of course, some contexts where a command, even an indirect one, is simply dis-preferred. When discussing gambling, an extremely popular traditional activity, I attempted to elicit the command to 'Place your bet!' and was instead offered the following, a question whose force amounts to that of a 'veiled' command:

(35) haa=nooko ii tigi-ki-kwi $\mathrm{Q}=$ amount/all you put.sG-APPLIC-FUT

How much will you bet?

Games of chance move very quickly, and any delay in playing one's turn is considered tantamount to cheating. This is the only instance I have found so far where an information question was offered as an optional command strategy, but there are no doubt other contexts where the use of interrogatives as veiled commands is appropriate.

\section{The prohibitive construction}

Prohibitives (negative commands) in Northern Paiute are formed by placing the negative particle kai (NEG) at the beginning of the clause and the prohibitive enclitic =paana (PROHIB) immediately after the verb, clause-finally.

(36) kai i=mubi-kwai-tu tsama=paana!

NEG $2=$ nose-LOC-ALL touch=PROHIB

Don't pick your nose!

(37) kai $u=$ tsitsuga=paana!

NEG 3 =point=PROHIB

Don't point at it! (of a rainbow)

Prohibitive strategies may deviate from the $\{\mathrm{kai} \mathrm{V}=$ paana $\}$ prototype. Although such variation typically includes the use of second position modal clitics and/or the overt use of second person pronouns, they do not involve the use of irrealis markers, for historical reasons I explore in $\$ 9$. The addition of a second position modal enclitic can alter the force of the prohibition to a stern deontic interdiction:

(38) kai=sa'a inata naanitama=paana,

NEG $=$ MOD hereabout mock=PROHIB

yau-ti yaisi iwa-u muhu-ga-'yu

here-LOC then many-OBL Owl-HAVE-PRED

(You) mustn't mock around, as there are lots of owls around here.

(ML: The Five Men Story, MNC)

In (38), the modal second position enclitic $=s a$ ' $a$ 'softens' the interdiction and the partitive demonstrative inata also makes the prohibited activity appear non-specific or undirected. 
Prohibitives are extremely common in traditional folktales, which centre on the violation of an interdiction and its consequences. Folktales themselves are the vehicles for instructing others on proper action, with Coyote serving as the quintessential example for wrong action. ${ }^{9}$

\section{Development of the prohibitive construction}

Prohibitive clauses are frequently, in the appropriate context, followed by a simpledirect (39) or polite-indirect (40) command.

(39) kai ti-tamihoi=paana; yabi-su piti-u! NEG APASs-late=PROHIB quick-ADV arrive.SG-PUNC

Don't be late; arrive on time!

(40) kai yotsi=paana; mau=sapa habi-dabi!

NEG arise=PROHIB DEM=MOD lie.SG-KEEP.ON

Don't get up; keep lying there (where you are)!

In fact, the negative particle in combination with the prohibitive enclitic serves this particular function only when directed to a second person subject. In non-prohibitive contexts with first or third person subjects, the prohibitive enclitic functions as a kind of disjunctive, counterfactual particle meaning 'but; however' as in the following pair of examples with a first person singular subject.

(41) ni kai su-kima=paana kimma

I NEG DESID-come=PROHIB come.DUR

I don't want to come, but (I am) coming.

(42) ni su-kima=paana kai

I DESID-come=PROHIB NEG

I want(ed) to come, but no.

Likewise, with a first person plural subject:

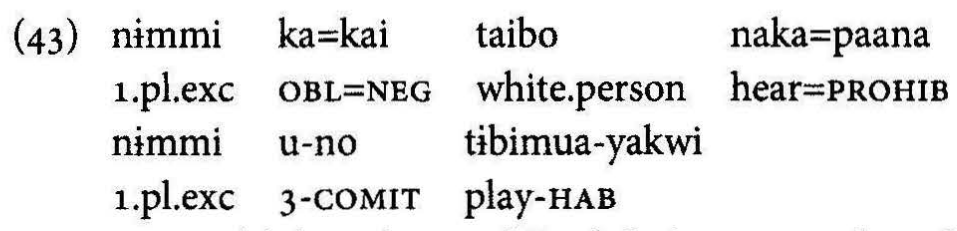

We couldn't understand English, but we used to play with him anyway.

(MS: Autobiography)

\footnotetext{
9 Indeed, the Northern Paiute verb tiničui means either 'to teach' or 'to tell stories'.
} 
Its role in conjoined clauses with a third person subject also finds it functioning as a disjunctive particle, as in (44):

(44) obi tia'a nimmi-nimi-'yakwi=paana kai mi=punni DEM thusly wander-RNDM.SG-HAB =PROHIB NEG PL=see.DUR ...so (he) would wander around, but didn't see them...

(NK: Boarding School Days)

Based upon examples such as those of (39)-(44), I would argue that the origin of the prohibitive construction is fundamentally biclausal. A concessive adverbial clause type, with either the declaration or concession marked by negation, sets the stage for the prohibitive construction with an unstated addressee as subject.

As further support for this proposal, the -na portion of the enclitic is clearly related to the pan-Uto-Aztecan participial/nominalizing suffix *-na, a marker of a variety of dependent clause types (Langacker 1977). The core semantic feature of -na is event simultaneity, a point that would not contradict the contexts above.

The remainder of the enclitic is likely cognate with the Ute (Southern Numic) 'irrealis' suffix (with allomorphs -vaa/-paa). According to Givón (2011), this suffix serves to 'mark more polite or less direct manipulative speech-acts, those of lower deontic force' (306). These include hortatives in Ute.

As pointed out in $\$ 8$, the prohibitive construction never co-occurs with the markers of irrealis found associated with the command strategies described earlier. This restriction on co-occurrence lends support to a relatively recent grammaticalization of the form. The presence of an older marker of irrealis that forms part of the prohibitive enclitic precludes other irrealis morphology, despite the fact that it is no longer productive in present-day Northern Paiute. The ${ }^{*}\{-p a a-n a\}$ combination is frozen, now carrying this more specialized, disjunctive/prohibitive function.

\section{Non-canonical directive: first person (ex)hortative}

Northern Paiute carries second position enclitics that express a wide range of modal and evidential functions as in (45)-(46).

(45) $\mathrm{mi}=$ naana=sakwa mi=timadzai

$\mathrm{PL}=$ men $=$ MOD $\quad$ 1.pl.exc $=$ help. $\mathrm{TR}$

The men should help us.

(46) $o o=$ kaina mi=tiya'i-pi miu ta na-ni-naka-ki-ti SO=MOD PL=die-PERV QUOT 1.du MID-IP/SPEECH-hear-APPLIC-GENL Perhaps those who have passed on want us to hear them. (NK: Old Voices)

As far as directive speech is concerned, first person directed speech, encoded as hortative constructions, utilizes one or another second position modal enclitic. 
The second position, deontic modal =sakwa in conjunction with either the first person plural or dual inclusive pronoun, comprises the most common form of the Northern Paiute hortative construction:

(47) tammi=sakwa winai-ga-kwi

1.pl.inc $=$ MOD throw.SG-TRNSL-FUT

Let's (three or more) go fishing!

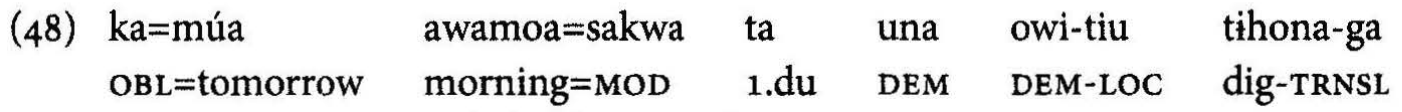
Tomorrow morning, let's (2) go out there to dig roots. (NK: Bear and Deer)

With first person singular subjects, there is an optative sense to the construction:

(49) 'ni=sakwa u=ma-mua-ga,' mii sunami

I=MOD 3.sg=IP/hand-play-TRNSL QUOT think.SG

'I oughta play a trick on him,' so thinking. (ML: Wildcat and Skunk, MNC)

Although =sakwa is the most common, others, especially =sapa and =sa' $a$, may also appear with first person directives:

(50) yau=sapa ta ti-yono

here $=$ MOD 1.du APASS-evening

Let us camp here.

(NK: Bear and Deer)

Since the inclusive plural and dual forms include a second person referent, they are the ones that appear in Northern Paiute hortatives.

There are occasions where the illocutionary force of a hortative requires only the use of a first person inclusive pronoun. Example (51) was an uttered response to (50):

(51) 'Aha, uu ta!' mii inakwi yes thusly 1.du.inc QuoT reply

'Yes, let's do that!' she replied.

(NK: Bear and Deer)

Variations on the primary hortative strategy include the use of irrealis (future or subjunctive) marking on the verb, as with Northern Paiute's canonical imperative.

(52) oo'no tika-kwi

at.that.time eat-FUT

Then (we) shall eat...

(Liljeblad 1966: 38)

(53) $\mathrm{u}=\mathrm{kwi}(\mathrm{h}) \dot{\mathrm{i}}$-tua-si tammi yau $(\mathrm{u}=)$ massia mii=tia'a.

3=grab-SUBJ-SEQ 1.sg.inc here (3=)plant QUOT=thusly

'We will get it and plant it here,' they said. (PS: tale 4, page 67, line 30, SLC) 
A suggestion to engage in a joint action can also be formulated by means of a clitic/ particle sequence that includes a combination of negative particle, question enclitic, second position modal enclitic, and inclusive pronoun.

$\begin{array}{lll}\text { (54) } \mathrm{kai}=\mathrm{ha}=\mathrm{sakwa}=\mathrm{ta} & \text { na-piti-ki-u, } & \text { mii=tia'a } \\ \mathrm{NEG}=\mathrm{Q}=\mathrm{MOD}=1 . \text { du.inc } & \text { MID-arrive.sG-APPLIC-PUNC } & \text { QUOT=thusly }\end{array}$

'Why don't we have a contest?' so saying. (NK: Porcupine and Coyote)

Note that both the suggestion (54) and the reply (55) include the punctual aspect suffix, compatible with modal enclitics.

(55) 'aha ni=sa'a mohi-mia-u,' mii=tia'a

yes I=MOD lead-go-PUNC QUOT=thusly

'All right, I shall go first,' so saying. （NK: Porcupine and Coyote)

The variety one finds in first-person-centred directive speech acts once again points to the lack of a single paradigm of grammatical imperative in Northern Paiute. That said, there are familiar elements that come into play-irrealis and/or punctual marking on the verb and the use of second position modals. I now turn to the non-canonical third person directive.

\section{Non-canonical directive: third person optative}

At first blush, the notion of a third person imperative would seem contradictoryhow does one offer or assert a directive to someone outside the message world of the speech act? Nevertheless, one often directs one's desires toward the actions performed or states entered into by others through optative-type constructions. ${ }^{10}$ These may be expressed via modals or conditional constructions, as in English 'May she do well!' or 'If only he would pay attention during lecture!'

I have found it difficult to identify examples of such a construction in my corpus of Northern Paiute recorded discourse. Nonetheless, one finds functionally optative constructions that utilize the future tense suffix in non-future contexts, as with the second line of $(56)$ :

(56)

$\begin{array}{llll}\text { su=nimi } & \text { yaisi pino'o } u=h i t t a-k i-s i & \text { pino'o } \\ \text { NOM=person } & \text { then also } & \text { 3=lift-APPLIC-sEQ } & \text { also } \\ \text { kosso-wai-tu } & \mathrm{u}=\text { tu'i-tsa-winai-hu-kwi-si } & \\ \text { fire-LOC-ALL } & \text { 3=try-IP/GRASP-throw-PUNC-FUT-SEQ }\end{array}$

The man, too, lifted that (skeleton) in turn, that (he) would try and throw it into the fire, and...

(ML: Five Men Story, MNC)

${ }^{10}$ As pointed out by an anonymous reviewer, optative constructions are not the only alternative to directing an imperative to a third person, and indeed, as described in the introduction to the present volume, such may exist in paradigmatic relationship to canonical addressee-directed commands. 
In Northern Paiute, one directs one's thoughts, or well wishes, toward a generic third party with the general expression, pis $a=t i a$ ' $a$ (good/well = thusly) 'may it be/as it is good'.

Further examples come from prayer. What is interesting is that the lines of the prayer are not in the form of direct entreaties or commands, but rather are statements regarding the favoured patterns of thought on the part of the participants and the expected outcomes of the actions taken up.

(57) pisa-u puni-no'o-kwi

good-oBL see-Go.ALONG-FUT

ni=tuami pisa maiku sutihai-no'o. mau!

1.pl=children good DEM bless-GO.ALONG in.that.way

...(what we) look toward is good, that our children may be blessed along the way. So be it!

(MP: Prayer 1)

Here we see a combination of future tense marking or irrealis potential and the directional suffix - no'o.

We now turn briefly to some points of comparison across the Numic subfamily in order to note some possible reconstructions, both morphologic and syntactic, of directive speech strategies, as well as some interesting points of variation. With these points, we hope to shed light both on earlier stages in the development of Northern Paiute and on features of typological interest. From these, I conclude with some general hypotheses on the development of directive speech acts.

\section{Historical considerations}

The bulk of the available material on other Numic languages describes imperatives as simply consisting of a bare verb stem and an unexpressed second person addressee, as with the canonical imperative in Northern Paiute. The basic imperative in Western Shoshoni (Central Numic), according to Crum and Dayley (1993: 9ff), is no exception, as seen in examples (58)-(59). The emphatic particle in $(59)^{11}$ serves to strengthen the command.

$\begin{array}{lllll}\text { (58) ukka tempitta tsahittsaa! } & \text { (59) } & \text { tsu mi'aku! } \\ \text { that-OBJ rock-OBJ lift } & \text { EMPH go.away } \\ \text { Lift up that rock! } & & \text { Leave! }\end{array}$

Interestingly, the two examples included by the authors of this latter strategy also end with the 'past, momentaneous completive' suffix $-k k u n,{ }^{12}$ a likely cognate of the Northern Paiute $-(h) u$ punctual suffix.

\footnotetext{
11 The graph $\{\mathrm{e}\}$, according to the source, stands for the back unrounded vowel [u], corresponding to Northern Paiute's high central unrounded vowel [i].

12 Orthographic morpheme-final consonants only surface in lexically specified contexts, affecting a following consonant, when present.
} 
Kawaiisu (Southern Numic), a language described in Zigmund, Booth, and Munro (1991), also carries a marker for bounded events in imperative constructions. The authors describe the use of the suffix $-n u$ in commands and state that the '[d]ifferences in meaning between imperatives with and without - nu can be attributed to the momentaneous meaning of this morpheme' (34). By way of example, an unbounded, atelic event expressed with the bare verb nukwi 'Run!' is set in contrast with the bounded, telic event expressed with the bare verb-plus-momentaneous suffix nooki-nu 'Bring it!

Indeed, the same verb root can be the core of the imperative expression, with or without the suffix, with the expected difference in meaning:

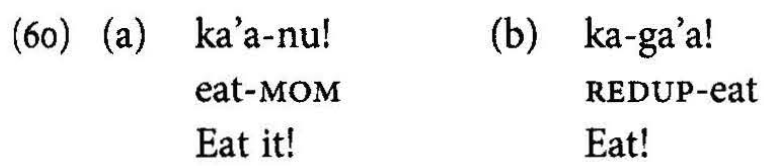

With a specific object implied, - nu appears, but is absent without one. Based on these preliminary observations, it appears likely that this function of the punctual suffix in commands can be reconstructed for proto-Numic.

Atypical subject coding in imperatives may arise, as we have seen, in cases of clausal nominalization (see example (31)). Two additional instances of atypical imperative subject marking may be found elsewhere in Numic. Suppletive verb stems in Western Shoshoni typically appear without an overt subject in the imperative, but when it is expressed, it is in the third person reflexive ${ }^{13}$ pronominal form rather than the second person dual or plural subject form (Crum and Dayley 1993: 10).

(61) aikkih peweh ne kemahka tsatsakki!

here 3.du.REFL me next.to stand.Du

Stand here beside me you two!

(62) aikkih pemme ne kemahka topo'i!

here 3.pl.REFL me next.to stand.PL

Stand here beside me you all!

Overt pronominal forms mainly appear in cases of dual or plural addressees.

In Southern Paiute, a Southern Numic language described in detail in Sapir (1930), but critically evaluated in Bunte (1979), imperative structures exhibit what some Uto-Aztecan language descriptions refer to as case switch, whereby theme or patient objects of transitive predicates appear in the nominative case. Consider the following:

(63) timp-ar mar $\quad$ yanwi-mi-ak
rock.NOM-ART that.NoM
Take that rock along!

13 These pronominal forms are only used for emphasis in Northern Paiute. The source indicated here does not include a description of that function for Western Shoshoni. 


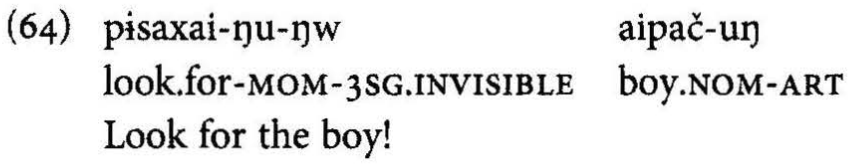

Note that the rock in (63) and the boy in (64) are notional objects of the imperative utterances. Bunte (1979: 91-6) treats the imperative as a voice construction on structural grounds, thusly aligning it with the more familiar, passive voice construction. As Bunte notes, however, 'the actual explanation has to do with topicality. The theme in imperative sentences is always topical' (1979: 94).

Historical connections between topicality and nominative case are not unusual, cross-linguistically, and can be found in Northern Paiute itself, which has innovated a nominative determiner proclitic $s u=$ from the emphatic enclitic $=s u$. The most likely bridge along this developmental pathway is the third person demonstrative usu, consisting of a deictic base and the erstwhile enclitic, marking the form as nominative. Bunte ascribes, on independent grounds, a topicality function to nominative case in Southern Paiute, also accounting for why examples like (63) and (64) are treated as a variety of voice construction.

Although I have not found straightforward examples in Northern Paiute of nominative-marked objects in commands such as those above, the following pair of examples could be so interpreted:

$\begin{array}{llllll}\text { (65) 'yaa } & \mathrm{i}=\text { =pabi'i } & \text { su=pisa } & \text { kama-di } & \text { yabi } & a=t \text { tika-hu,' } \\ \text { here } & 1 . \text { sg=eld.bro } & \text { NOM=good } & \text { taste-NOMz } & \text { hurry } & \text { 4=eat-PUNC }\end{array}$

'Here, my brother! That which tastes good, hurry and eat it!' (so he said)...

(PS: tale 11, page 197 , line 54, SLC)

(66)
tai'na=yaisi
paa-wa'ni
na-paa
su=tiba
thin=then
water-sIMIL MID-make.soup NOM=pinenut
Make the pinenuts into a soup as thin as water.

(PS: tale 4 , page 66 , line 18, SLC)

With example (65), nominative case marking appears on a headless subject relative clause meaning 'that which tastes good', regardless of its role in the main imperative clause. Likewise, with (66), the imperative clause is cast in the passive, and so could be interpreted as, 'Thin like water, the pinenuts are made (into) soup', independently motivating the nominative case form here.

As we have already seen, overt expression of the addressee may appear as formally non-subjects, morpho-syntactically. Notional objects appearing in the nominative case, on the other hand, cannot simply be explained by appealing to nominalization as we saw with examples (29)-(31). Rather, I would argue that by considering the biclausal origins of many constructions associated with directive speech acts, we come closer to a unified explanation of the grammar of directives. As we have seen 
above, this grammar bears a great deal of resemblance to the subordinate half of a biclausal construction elsewhere in the language, and so we need not be too surprised that grammatical relations may be differentially encoded.

A more detailed discussion and analysis of directive speech, especially command strategies, throughout the subfamily is needed, since at present only minimal attention has been given to these construction types in the published literature on these languages.

The Northern Paiute \{kai V=paana\} prohibitive construction, whose historical development was detailed in $\$ 9$, is mirrored most closely in Kawaiisu (Southern Numic). The formal pattern for Kawaiisu includes the negative particle kedu followed by the bare verb stem-plus-prohibitive enclitic =vine'e.

Northern Paiute's nearest relative in Western Numic, Mono, is described in Lamb (1958) as having a prohibitive construction consisting of a special negative form mino' $o$ at the beginning of the clause and a clause-final verb marked with either -tyh or $-n e h$. Both suffixes have clear cognates throughout Numic as general tense markers or nominalizers. The Central Numic languages, Comanche (Charney 1993) and Western Shoshoni (Crum and Dayley 1993), form the prohibitive construction with a cognate of the Uto-Aztecan negative particle ${ }^{*} k e$ and the final suffix -te(n), a panNumic nominalizer.

Looking across the Numic subfamily, therefore, we find evidence for a protoNumic prohibitive construction consisting of a negative particle and a subordinate verb form.

To conclude this preliminary exploration of directives among Northern Paiute's nearest relatives, we see very little information to draw on regarding non-canonical directives, such as hortative constructions, elsewhere in Numic. Givón (2011) describes the hortative in Ute as involving the suffixation of the 'appropriate ${ }_{2}^{\text {nd }}[$ sic $]$ person inclusive subject pronoun to the verb or to the first word in the clause' (306). Although it is clear by the examples provided it is the first person dual and plural inclusive forms that are used, the second position enclitic status of the pronoun is less clear. Also, as discussed above, the irrealis suffix -vaa/-paa is utilized to mark 'lower epistemic certainty' in this construction in Ute.

\section{Summary and conclusion}

Northern Paiute exhibits a fair amount of formal and pragmatic variety in directive speech, but no dedicated paradigmatic structure supporting it. In looking at a range of command strategies, whether canonical or non-canonical, one finds many familiar elements-irrealis marking, overlap with deontic modality, nominalized (desubordinated) clauses, etc. Many of the constructions, if not the forms themselves, can be reconstructed for Numic. Future research will be necessary to expand developmental 
pathways to Uto-Aztecan as a whole, but it is clear that there are cycles of renewal at work here, whereby functionally, if not always formally, related elements enter into the grammar of directive speech across the family.

Considering the history, and heterogeneity, of Northern Paiute directive speech acts has also proven productive in unveiling their origins as parts of biclausal constructions. These dependent, often nominalized, constructions qua directive speech acts make for an intriguing counterpoint to a substantial literature regarding the development of syntactic complexity (Karlsson and Miestamo 2008; Givón and Shibatani 2009; inter alia). Commands and command strategies, I would argue, make interesting fodder for studying the development of syntactic simplicity from familiar complex syntactic pathways. A thorough study of directive speech across the Uto-Aztecan family can only be undertaken once detailed analyses of canonical and non-canonical commands and command strategies are described, formally and functionally, in the individual languages.

\section{Acknowledgements}

Institutional support for this work has been provided by National Science Foundation grant \#0418453 and by the Sven and Astrid Liljeblad foundation for Great Basin studies.

With humility, I express gratitude to my language teachers, including Rena Adams Beers, Ruth Hoodie Lewis, Patricia Teeman Miller, Shirley Tufti, Phyllis Harrington Miller, and Yolanda Manning. I remain deeply grateful to have had the occasion to learn from the late Irwin Weiser (1909-96), Maude Washington Stanley (1913-2000), Myrtle Louie Peck (1934-2006), Nepa Kennedy (1918-2010), Justine Louie Brown (1918-2011), and Lloyd Louie (1936-2013).

Many thanks to Sasha Aikhenvald and Bob Dixon for their insights and encouragement and to all the participants in the International 'Commands' Workshop in Cairns, Australia. Thanks also to an anonymous reviewer for their helpful comments. I bear sole responsibility for any errors of analysis and interpretation.

\section{References}

Aikhenvald, Alexandra Y. 2010. Imperatives and commands. Oxford: Oxford University Press. Aikhenvald, Alexandra Y. and Dixon, R. M. W. 2006. Editors of Serial verb constructions: A cross-linguistic typology. Oxford: Oxford University Press.

Brown, Penelope and Levinson, Stephen C. 1987. Politeness: Some universals in language usage. Cambridge: Cambridge University Press.

Bunte, Pamela. 1979. Problems in Southern Paiute syntax and semantics. PhD Dissertation, Indiana University.

Charney, Jean Ormsbee. 1993. A Grammar of Comanche. Lincoln: University of Nebraska Press. 
Corbett, Greville G. 2000. Number. Cambridge University Press.

Crum, Beverly and Dayley, Jon. 1993. Western Shoshoni grammar. Boise State University.

Givón, T. 1990. Syntax: A functional-typological introduction. Vol. 2. Amsterdam: John Benjamins.

Givón, T. 2011. Ute reference grammar. Amsterdam: John Benjamins.

Givón, T. and Shibatani, Masayoshi. 2009. Editors of Syntactic complexity: Diachrony, acquisition, neuro-cognition, evolution. Amsterdam: John Benjamins.

Haiman, John. 2003. 'Iconicity', pp. 453-6 of Encyclopedia of cognitive science, edited by Lynn Nadel. London, New York, and Tokyo: Nature Publishing Group.

Karlsson, Fred and Miestamo, Matti. 2008. Editors of Language complexity: Typology, contact, change. Amsterdam: John Benjamins.

König, Ekkehard and Siemund, Peter. 2007. 'Speech act distinctions in grammar', pp. 276-324 of Language typology and syntactic description, Vol. 1, Clause structure, 2nd edition, edited by Timothy Shopen. Cambridge: Cambridge University Press.

Lamb, Sidney M. 1958. Mono grammar. PhD Dissertation, Berkeley: University of California.

Langacker, R. W. 1977. Studies in Uto-Aztecan grammar, Vol. 1, An overview of Uto-Aztecan grammar. Arlington, TX: SIL Publications.

Liljeblad, Sven. no date. 'Grammatical notes.' University of Nevada at Reno: Archives. Manuscript.

Liljeblad, Sven. 1966. Northern Paiute manual: Grammatical sketch of the northern dialects. Manuscript.

Norris, Evan J. 1986. A grammar sketch and comparative study of Eastern Mono. $\mathrm{PhD}$ Dissertation. San Diego: University of California.

Sapir, Edward. 1930. 'Southern Paiute: A Shoshonean language', American Academy of Arts and Sciences 65: 1-296. Reprinted in The collected works of Edward Sapir X: Southern Paiute and Ute linguistics and ethnography, edited by William Bright. New York: Mouton de Gruyter.

Snapp, A. and Anderson, J. 1982. 'Northern Paiute', pp. 1-92 of Studies in Uto-Aztecan grammar, Vol. 3, Uto-Aztecan grammatical sketches, edited by R. W. Langacker. Dallas: SIL Publications.

Thornes, Tim. 2003. A grammar of Northern Paiute with texts. PhD Dissertation, University of Oregon, Eugene.

Thornes, Tim. 2009. 'Historical pathways in Northern Paiute verb formation', pp. 295-320 of New challenges in typology: Transcending the borders and refining the distinctions, edited by Patience Epps and Alexandre Arkipov. Berlin and New York: Mouton de Gruyter.

Thornes, Tim. 2011. 'Dimensions of Northern Paiute multi-verb constructions', pp. 27-61 of Multi-verb constructions: $A$ view from the Americas, edited by Alexandra Y. Aikhenvald and Pieter Muysken. Leiden and Boston: Brill Publishing.

Thornes, Tim. 2012. 'Functional underpinnings of diachrony in relative clause formation: The nominalization-relativization connection in Northern Paiute', pp. 147-70 of Relative clauses in languages of the Americas: A typological overview, edited by Bernard Comrie and Zarina Estrada Fernández. Amsterdam: John Benjamins.

Thornes, Tim. 2013. 'Causation as "functional sink" in Northern Paiute', pp. 237-57 of Functional-historical approaches to explanation: In honor of Scott DeLancey, edited by 
Tim Thornes, Erik Andvik, Gwendolyn Hyslop, and Joana Jansen. Amsterdam: John Benjamins.

Zigmund, Maurice L.; Booth, Curtis G.; and Munro, Pamela. 1990. Kawaiisu: A grammar and dictionary with texts. University of California Publications in Linguistics, Vol. 119. Berkeley: University of California Press. 